\title{
Prevalence of strabismus among students in Natal/RN - Brazil
}

\author{
Prevalência de estrabismo nos estudantes de Natal/RN-Brasil
}

\author{
Carlos Alexandre de Amorim Garcia ${ }^{1}$ \\ Araken Britto de Sousa ${ }^{2}$ \\ Marcelo Bezerra de Melo Mendonça ${ }^{2}$ \\ Luciana Luna de Andrade ${ }^{2}$ \\ Fernando Oréfice ${ }^{3}$
}

${ }^{1}$ Coordinator, Medical Residence Ophthalmology Program, Hospital Universitário Onofre Lopes - HUOL Universidade Federal do Rio Grande do Norte - UFRN; Professor of Ophthalmology Universidade Federal do Rio Grande do Norte - UFRN.

${ }^{2}$ Medical Resident in Ophthalmology, Universidade Federal do Rio Grande do Norte - UFRN

${ }^{3}$ Professor of Ophthalmology, Universidade Federal de Minas Gerais - UFMG.

Address to correspondence: Carlos Alexandre de Amorim Garcia, Rua Ceará Mirim, 316 - Natal (RN) CEP 59020-240

E-mail: prontoc.de.olhos@digi.com.br

Nota Editorial: Pela análise deste trabalho e por sua anuência na divulgação desta nota, agradecemos ao Dr. Renato Luiz Nahoum Curi.

Recebido para publicação em 19.12.2003

Versão revisada recebida em 19.04.2004

Aprovação em 23.04.2004

\begin{tabular}{|l|}
\hline ABSTRACT \\
\hline Purpose: To estimate the prevalence of strabismus in Natal, Brazil, among \\
elementary and high school students of the public and private educational \\
systems, in addition to detecting etiological factors. Methods: 1024 students \\
were randomly selected and submitted to a questionnaire and a complete \\
ophthalmologic examination, by professors and resident physicians in \\
Ophthalmology at the Federal University of Rio Grande do Norte. Results: \\
Of 1024 students, 1015 were examined; 29 were found to have strabismus \\
(2.9\%), 20 of whom had manifest exotropia ( $2 \%), 2$ had intermittent \\
exotropia ( $0.2 \%), 6$ had esotropia ( $0.6 \%)$ and 1 had V anisotropies $(0.1 \%)$. \\
Conclusions: The strabismus prevalence of the student population of \\
Natal falls within the range of the worldwide population. There was ocular \\
lesion in only one student (retinochoroiditis scar on the posterior pole in \\
both eyes) related to strabismus.
\end{tabular}

Keywords: Strabismus/epidemiology; Strabismus / prevention \& control; Eye health; School health services; Students

\section{INTRODUCTION}

Strabismus consists of any deviation of binocular alignment and is present in 2 to $4 \%$ of the world's child population ${ }^{(1-2)}$. Strabismus can be both cause and effect of poor binocularity and, when it appears in the early years of life, may lead to states of sensorial adaptation such as retinic correspondence anomaly and amblyopia; on the other hand, if strabismus arises after binocular vision development, diplopia and image confusion appears, which persists indefinitely or until motor alteration is corrected ${ }^{(3)}$. We also encountered, as a consequence of strabismus, postural deformities of the head ${ }^{(4)}$.

Treatment for strabismus should be initiated as soon as it is diagnosed, in order to achieve the best binocular vision possible, as well as for esthetic purposes, thus preventing or diminishing psychological disorders, for, according to Vaughan, no strabismus is spontaneously cured ${ }^{(2)}$.

The school environment allows for the development of preventive measures in promoting ocular health and early diagnosis and treatment of ophthalmological disorders. In this context, its importance is emphasized in developing educational strategies for preservation and restoration of the students' visual system. Early detection, resolution or minimization of ophthalmological disorders in school-age children can be achieved, thus preventing adverse consequences for the intellectual, social and psychological development of the individual. 
Every child should undergo an ophthalmological examination during pre-school or early school years, thus increasing the resolution of detected ophthalmological disorders since the child's visual apparatus is in full development ${ }^{(5)}$.

Frequently, in developed countries where programs of visual screening already exist, some ocular disorders, such as amblyopia, are becoming less and less common ${ }^{(6)}$. Such programs bring unquestionable benefits to society as well as to science.

The objective of this study is to establish the prevalence of strabismus in a student population of primary and secondary schools, both public and private in Natal, Brazil, as well as detecting etiological factors for posterior prevention of strabismus.

\section{METHODS}

This is a cross-sectional study, in which the sample was randomly selected. It consisted of people between the ages of 5 and 46 years, enrolled in elementary or high schools, of the private or public system in Natal, Brazil, in 2001.

Four samples were considered for the methodological study, corresponding to the four districts into which Natal is divided: North, South, East and West.

The student population in 2001 was 196.116 , distributed by district and type of institution (public or private).

The methodological procedure for the sample selection was in two stages:

Stage I: Determining the sample size;

Stage II: Random selection of schools and their respective students.

The size of the general sample of 1024 students was distributed proportionally among the four districts. Thereafter, the number of schools and which of these would be selected from each district, was determined by the Proportional Probability of Size method (PPS), taking into consideration the type and level of each school. Of 341 schools, 79 were selected, from which the number of students per study period and number of students per grade level were selected, the selection being taken from the school attendance list, with the help of a random number of people generating computer program.

The students answered a standard questionnaire, collected by medical professors and residents in Ophthalmology at UFRN, providing names, socioeconomic level as well as personal and familial nosologic data.

The 1024 students underwent an ophthalmological examination which included: measuring visual acuity, diagnostic tests for strabismus (Hirschberg, Krimsky and cover tests), refraction (retinoscopy under cycloplegia), biomicroscopy, tonometry and funduscopy.

For the of statistical analysis, relative and absolute frequency of the study variables were calculated, and the data were processed by the SPSS computer program (Statistical Package for Social Science) Data Editor 10.0.

\section{RESULTS}

Of the 1024 students who underwent the interview and ophthalmological examination, 9 were excluded for lack of research protocol data, leaving 1015 individuals that were studied. Age varied from 5 to 46 years, with an average of 16 years, with a standard deviation 4.50 (Graph 1). In relation to sex, a slight predominance of females was observed (59.3\%).

Of the 1015 students, 986 were orthophoric (97.1\%), and 29 patients had strabismus $(2.9 \%)$, of these 20 had exotropia (2\%), 2 intermittent exotropia (0.2\%), 6 esotropia (0.6\%) and 1 $(0.1 \%)$ had $\mathrm{V}$ anisotropia (Table 1$)$.

Strabismus was most prevalent in patients with 10 to 20 years of age. After 21 years, no case of strabismus was observed (Table 2).

Upon analyzing the measurement of ocular deviation in prism diopters, the exodeviation varied from micro (1 to 8 P.D.) to 50 P.D. with an average of 16.25 P.D. and the esodeviation varied from micro (1 to 8 P.D.) to 40 P.D. with an average of 15.5 P.D. It was observed that 9 patients $(31 \%)$ had exotropia of 15 prismatic diopters, while the other types were uniformly distributed, with a frequency of 1 to 3 patients (Table 3). One patient with orthophoria showed a V anisotropia of 15 P.D. Another patient with exotropia of 12 P.D. also showed a right hypertropia of 8 P.D. and finally another patient with exotropia of 50 P.D. also showed a V anisotropia of 20 P.D.

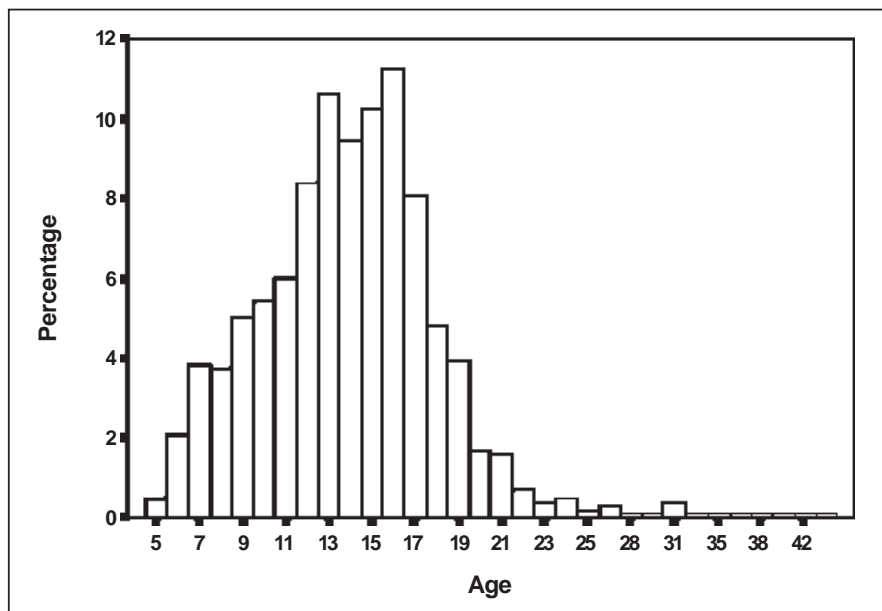

Graph 1 - Age frequency of 1015 students in Natal, Brazil in 2001

Table 1. Frequency of the oculomotor findings of 1015 students in Natal, Brazil in 2001

\begin{tabular}{lcc} 
Strabismus type & Frequency & Percentage \\
Exotropia & 20 & 2.0 \\
Intermittent exotropia & 2 & 0.2 \\
Esotropia & 6 & 0.6 \\
V anisotropia & 1 & 0.1 \\
Total & $\mathbf{2 9}$ & $\mathbf{2 . 9}$ \\
\hline
\end{tabular}




\begin{tabular}{|c|c|c|c|c|}
\hline \multirow[b]{2}{*}{ Age } & \multicolumn{3}{|c|}{ Strabismus } & \multirow[b]{2}{*}{ Total } \\
\hline & Exodeviation & Esodeviation & V Anisotropia & \\
\hline 5 to 10 & $2(0.2 \%)$ & $1(0.1 \%)$ & 0 & $3(0,3 \%)$ \\
\hline 11 to 15 & $10(1.0 \%)$ & $3(0.3 \%)$ & 0 & $13(1,3 \%)$ \\
\hline 16 to 20 & $10(1.0 \%)$ & $2(0.2 \%)$ & 0 & $13(1,3 \%)$ \\
\hline 21 to 46 & 0 & 0 & $1(0.1 \%)$ & 0 \\
\hline Total & 22 (2.2\%) & $6(0.6 \%)$ & $1(0.1 \%)$ & $29(2,9 \%)$ \\
\hline
\end{tabular}

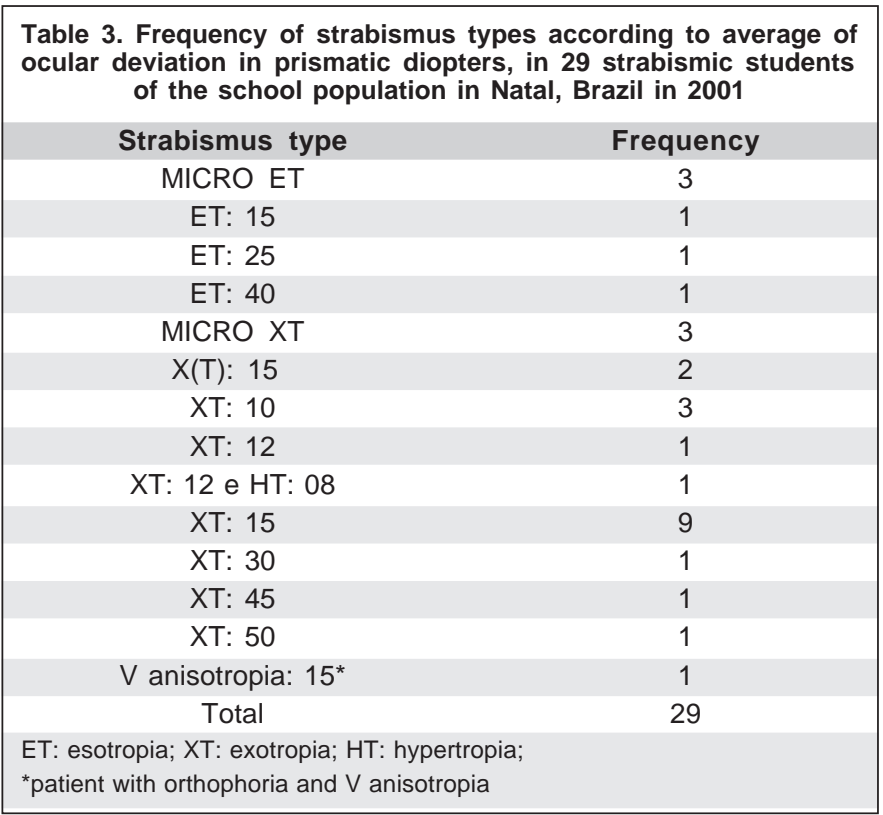

The following variables like age, sex, skin color, social level, refraction and previous ocular disorder history, were studied, however, no result presented statistical significance.

The medical charts of 29 students with strabismus were analyzed, with the following results: 25 (86\%) had visual acuity (with or without optic correction) of 20/20 (both eyes) to $20 / 20 \times 20 / 30$ and $4(14 \%)$ presented some degree of amblyopia (Table 4), with all the amblyopic students having exodeviation (XT).

In only one patient a focus of retinochoroiditis in the posterior pole of both eyes was found, with visual acuity: right eye: 20/30 and left eye: counting fingers at 3 meters.

\section{COMMENTS}

The prevalence of strabismus in the student population of Natal, Brazil was $2.9 \%$, agreeing with some authors, who have reported prevalence between 2 and $4 \%^{(1)}$. Similar studies have been performed in other places, such as in Baltimore, with $3.1 \%$ in $1996^{(7)}$ and $3.2 \%$ in $1998^{(8)}$ and in Sweden, $2.7 \%{ }^{(6)}$. In Ibipora, Brazil, the prevalence was $0.84 \%{ }^{(9)}$ and in Tanzania it was $0.5 \%(10)$, less than the variation of 2 to $4 \%$. However, in
Cambridge, the prevalence was $13.2 \%(11)$, greater than the previously mentioned variation, this being a study based on visual selection.

The vast majority of strabismus cases were of the divergent type, with 20 cases of permanent exotropia (2\%) and 2 with intermittent exotropia $(0.2 \%)$ (Table 1$)$, similar only to a study in Labrador $^{(12)}$ and contradicting the greater part of the literature, where esodeviation prevails over exodeviation ${ }^{(1,6-9,13-14)}$.

According to Duane, strabismus distribution is from 2 to $4 \%$ for esotropia and from 0.5 to $1 \%$ for exotropia ${ }^{(15)}$. Racial differences are observed. Esotropia is more common in the white population, while exotropia is more common among blacks and Asians. In mixed-race individuals, the division between convergent and divergent strabismus is more regular.

The age range of greatest strabismus prevalence was from 10 to 20 years, for both esodeviation and exodeviation. In relation to permanent esotropia and intermittent exotropia, the literature shows the greatest prevalence from 6 months to 4 years ${ }^{(1,16-18)}$, not coinciding with results obtained in this study; however, permanent exotropia may be present at birth or appear at a later date. According to Barbosa, when permanent exotropia is of the secondary type, deterioration of intermittent exotropia arises between 6 and 15 years and in the earlier phases manifests itself as esotropia ${ }^{(16)}$.

In most population studies individuals undergo visual selection, as a test of visual acuity performed by technicians or trained school employees and only individuals with some visual alteration respond to research protocol questions and are submitted to an ophthalmological examination by ophthalmologists.

This study, applying questionnaires and ophthalmological examinations to all individuals, revealed a low occurrence of amblyopia in strabismic students (14\%) (Table 4).

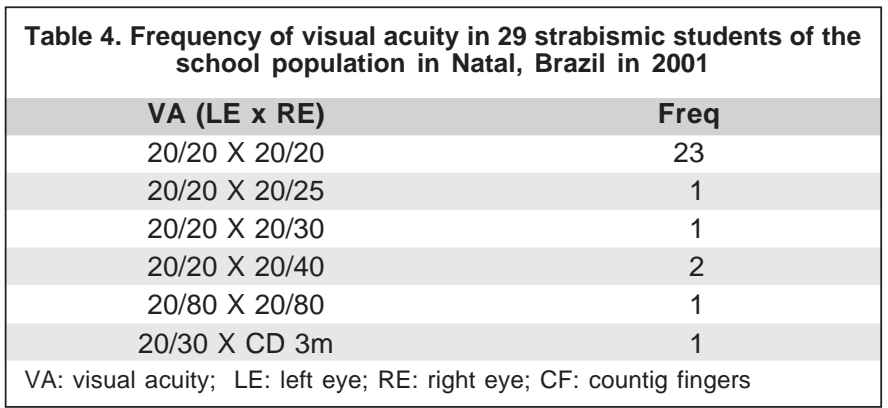


All students with visual acuity less than 20/20 X 20/30 had permanent exotropia. According to Bicas, strabismic amblyopia has a functional explanation initially (visual suppression when ocular misalignment occurs to avoid diplopia and confusion) and morphologic subsequently ${ }^{(3)}$ (cellular alterations in the lateral geniculate body and in the visual cortex $)^{(3)}$.

According to Procianoy, as a consequence of the constancy of the divergence deviation, there is a greater incidence of amblyopia in permanent exotropia in relation to intermittent exotropia; thus clinical treatment of permanent exotropia (amblyopia treatment) must be undertaken as early as possi$\mathrm{ble}^{(17)}$. A low visual acuity in one eye favors ocular deviation; if it occurs prior to 8 years of age, the tendency is towards esodeviation; after that age it favors exodeviation. Such patients with esodeviation may change, later on, to exodeviation.

In a study performed in Baltimore, different from this paper, all but onestrabismus cases associated with amblyopia were esotropic ${ }^{(7)}$. As to amblyopia etiology, $44 \%$ of the cases were attributed to strabismus. In Sweden, Kvarnstrom ${ }^{(13)}$ observed that strabismus was responsible for $21 \%$ of amblyopia cases and Ohlsson ${ }^{(6)}$ showed that $29 \%$ of the children with a diagnosis of strabismus were amblyopic. In Brazil, in a study carried out in Ibipora, Paraná, 20.68\% of amblyopic students presented strabismus ${ }^{(9)}$.

Some conditions are known to favor the appearance of strabismus, such as high ametropia (hyperopia more than myopia), anisometropia, cranial-facial or ocular malformations, corneal opacities, cataract, disease of the oculomotor nerve or optic pathways ${ }^{(1)}$. In our study, the only condition observed which justified strabismus was the presence of retinochoroiditis scars, in one case.

With the exception of one case (a student who presented a retinochoroiditis focus in the posterior pole of both eyes), there were no ocular lesions in the students, associated with strabismus and amblyopia; probably exotropia was the cause of amblyopia. Thus, amblyopia could have had its incidence minimized with specific early treatment.

\section{RESUMO}

Objetivos: Avaliar a prevalência de estrabismo do município de Natal, entre os estudantes de I e II graus das escolas públicas e privadas, e detectar os possíveis fatores etiológicos. Método: 1024 alunos foram escolhidos de forma aleatória, sendo submetidos a um questionário e a um exame oftalmológico completo, pelos médicos docentes e residentes em Oftal- mologia da UFRN. Resultados: Dos 1024 estudantes, foram analisados 1015; 29 eram portadores de estrabismo $(2,9 \%)$, sendo 20 com exotropia manifesta ( $2 \%), 2$ com exotropia intermitente $(0,2 \%), 6$ com esotropia $(0,6 \%)$ e 1 com anisotropia em V $(0,1 \%)$. Conclusões: A prevalência de estrabismo da população de estudantes de Natal é semelhante a estudos de prevalência publicados anteriormente. Em apenas um dos estudantes havia lesão ocular (cicatriz de retinocoroidite em pólo posterior de ambos os olhos) causando estrabismo.

Descritores: Estrabismo/epidemiologia; Estrabismo/prevenção \& controle; Saúde ocular; Serviços de saúde escolar; Estudantes

\section{REFERENCES}

1. Ribeiro CMS. Estrabismo: classificação e etiopatogenia. In: Souza-Dias CR, Almeida HC. Estrabismo. São Paulo: Roca; 1998. p.71-3.

2. Asbury T, Burke MJ. Estrabismo. In: Vaughan D, Asbury T. Oftalmologia geral. 4 ed. São Paulo, Atheneu; 1998. p.226-44.

3. Bicas HEA. Visão binocular e estrabismo. Arq Bras Oftalmol. 1987;50(1):36-41

4. Bicas HEA, Caldeira JAF, Campos WR, Carvalho KMM, Cukierman S, Cunha RL et al. Rotina de exames do estrabismo: caderno 3. Arq Bras Oftalmol. 1987;50(1):13-35.

5. Figueiredo RM, Santos EC, Almas de Jesus IA, Castilho RM, Santos EV. Proposição de procedimento de detecção sistemática de perturbações oftalmológicas em escolares. Rev Saude Publica. 1993;27(3):204-9.

6. Ohlsson J, Villarreal G, Sjostrom A, Abrahamsson M, Sjostrand J. Visual acuity, residual amblyopia and ocular pathology in a screened population of 1213-year-old children in Sweden. Acta Ophthalmol Scand. 2001;79(6):589-95.

7. Preslan MW, Novak A. Baltimore Vision Screening Project. Ophthalmology. 1996;103(1):105-9.

8. Preslan MW, Novak A. Baltimore Vision Screening Project. Phase 2. Ophthalmology. 1998;105(1):150-3.

9. Schimiti RB, Costa VP, Gregui MJF, Kara-José N, Temporini ER. Prevalence of refractive errors and ocular disorders in preschool and schoolchildren of Ibiporã-PR, Brazil (1989 to 1996). Arq Bras Oftalmol. 2001;64(5):379-84.

10. Wedner SH, Ross DA, Balira R, Kaji L, Foster A. Prevalence of eye diseases in primary school children in a rural area of Tanzania. Br J Ophthalmol. 2000;84(11):1291-7.

11. Newman DK, Hitchcock A, McCarthy H, Keast-Butler J, Moore AT. Preschool vision screening: outcome of children referred to the hospital eye service. Br J Ophthalmol. 1996;80(12):1077-82.

12. Johnson GJ, Green JS, Paterson GD, Perkins ES. Survey of ophthalmic conditions in a Labrador community: II. Ocular disease. Can J Ophthalmol. 1984;19(5):224-33.

13. Kvarnstrom G, Jakobsson P, Lennerstrand G. Visual screening of Swedish children: an ophthalmological evaluation. Acta Ophthalmol Scand. 2001; 79(3):240-4.

14. Sá LCF. Estrabismo nos anos 90. Arq Bras Oftalmol. 1998;61(6):720-4.

15. O'Hara AM, Nelson LB. Heredity of strabismus. In: Tasman MDW. Duane's Ophthalmology. [monography on CD-ROM]. New York: Lippincott; 1995.

16. Almeida HC: Exodesvios, In: Barbosa PH. Estrabismo. Rio de Janeiro: Cultura Médica; 1997. p.119-23. (Biblioteca Brasileira de Oftalmologia).

17. Procianoy E. Exotropias. In: Souza-Dias CR, Almeida HC. Estrabismo. $2^{a}$. ed. São Paulo: Roca; 1998. p.145-52.

18. Barbosa PH. Estrabismo. Rio de Janeiro; Cultura Médica, 1997. 113p. (Biblioteca Brasileira de Oftalmologia).

\section{Nos artigos enviados para publicação, o nome dos autores e suas afiliações devem estar completos. Isso facilitará a indexação e os links com as bases de dados e o CV Lates.}

